\title{
La responsabilidad de las empresas en los contratos tercerizados de construcción
}

María Georgina Parrales Iglesias 88

Universidad Nacional del Nordeste de Argentina

mgparrales@hotmail.com

\section{Resumen}

Actualmente existe un auge de los proyectos habitacionales y de comercio en el país, lo que ha conllevado a que los contratos comerciales entre empresas desarrolladoras y constructoras aumenten y surjan nuevas formas jurídicas de contratación como es el caso de la tercerización; figura que se intenta regular en el "Proyecto de Ley de Regulación y Ordenamiento de la Tercerización, Subcontratación e Intermediación del Empleo", que se encuentra en revisión desde el año 2009 en la Asamblea Nacional de Nicaragua y que se hace necesaria su aprobación e implementación para que exista unicidad entre las diferentes instituciones del Estado que fiscalizan el cumplimiento de las normas laborales, no sin antes de terminar de definir las figuras de tercerización, subcontratación e intermediacion ya que estas dos últimas se encuentran reguladas en el Codigo de Trabajo de Nicaragua, y por tanto lo que se hace necesario primero es precisar qué es tercerización ya que existe confusión en su definición y características, no sólo entre las instituciones del Estado sino entre las empresas y los mismos trabajadores; asimismo, se debe puntualizar las responsabilidades de cada empresa actora de los contratos de tercerización, máxime cuando se crean los requisitos para actuar como empresa tercerizante y que se deben cumplir para que los derechos laborales no sean infringidos.

\section{Palabras clave}

Tercerización / empresa usuaria o principal / empresa tercerizante / responsabilidad solidaria o subsidiaria

${ }^{88}$ La autora es graduada de la Maestría en Derecho de Empresa con Especialización en Asesoría Jurídica de la Universidad Centroamericana, Nicaragua. 
Nowadays, there has been a boom in housing projects and trading in the country, which had led development companies and construction companies to increase and emerge to new legal forms of hiring such as outsourcing within the commercial contracts; still without a regulation and with an attempt to do so with "Regulation and Management of outsourcing Law Project, Subcontracting and Employment intermediation", which is under revision since 2009 at the National Assembly of Nicaragua. It's approval and implementation is necessary for uniqueness between all State Institutions who monitor the labor policy compliance, not defining beforehand what we know as outsourcing, subcontracting and intermediation. These last two are regulated by the Labor Code of Nicaragua, therefore is the need to precise what exactly Outsourcing is, due to a confusion on its own definition and characteristics, not only among the State Institutions but within the private companies and employees as well. In addition, to point out the companies liability on the agreement, especially when there are requirements to operate as an outsourcing company in order to avoid the labor rights to be transgressed.

User company / Outsourcing Company / Joint liability / Secondary liability

\section{Tabla de contenido}

I. Introducción. Situación de proyectos constructivos en Nicaragua; 2. Análisis de Proyecto de Ley General de Regulación y Ordenamiento de la Tercerización, Subcontratación e Intermediación del Empleo; 2.I. Definición de tercerización; 2.2. Deberes de las empresas tercerizantes; 2.3. Tercerización entre empresas relacionadas; 2.4 . Responsabilidad Solidaria; 3. Régimen de las empresas partes y rol de las instituciones públicas; 3.I. Empresa usuaria o principal; 3.2. Empresa constructora o tercerizante; 3.3. Trabajadores o mano de obra; 3.4. El rol del Ministerio de Trabajo (MITRAB); 3.5. El rol del Instituto Nicaragüense de Seguridad Social (INSS); 3.6. El rol del Instituto de la Vivienda Rural y Urbana (INVUR); 4. Conclusiones; 5. Recomendaciones. Anexo: "Proyecto de Ley General de Regulación y Ordenamiento de la Tercerización, Subcontratación e Intermediación del Empleo”.

\section{Introducción. Situación de proyectos constructivos en Nicaragua}

Con la proliferación de proyectos habitacionales que se ha presentado en los últimos años en Nicaragua, se busca analizar si las leyes laborales cumplen con los derechos de la mano de obra en la construcción. Por tanto, la presente investigación tiene como objetivo determinar la responsabilidad de las empresas desarrolladoras de proyectos habitacionales o de comercio, y constructoras, en los contratos tercerizados de construcción, mediante el análisis del Proyecto, determinando si el mismo busca cumplir con los derechos laborales y la responsabilidad de las empresas como garante de los mismos, estableciendo al final recomendaciones que coadyuven a mejorar las relaciones entre las partes en el gremio de la construcción a la luz de la ley. 
Se revisarán las leyes en materia laboral vigente en la legislación nicaragüense y el Proyecto, así como material que regulan las relaciones laborales y más específicamente la figura de la tercerización, haciendo una relación con el derecho comparado con el fin de establecer si el Proyecto mejora las leyes laborales en este tipo de contrataciones y como se pueden definir y establecer una mejor regulación de la figura de la tercerización.

\section{I.I Consideraciones generales de justificación para el estudio "La responsabilidad de las empresa en los contratos de tercerización"}

De acuerdo a un estudio de mercado, realizado por la firma M\&R en agosto de 20I5, en las ciudades de Managua, León, Chinandega y Estelí existe un $66.8 \%$ entre las personas encuestadas con mucho interés de adquirir una vivienda en un futuro cercano, siendo un factor predominante para el $\mathbf{8 8 . 5 \%}$ de los encuestados para adquirirlas, las condiciones de infraestructura de la vivienda, es decir, la importancia de contar con una adecuada construcción. Conllevando a buscar diferentes opciones para poder obtener una vivienda, ya sea mediante un crédito hipotecario así como el acceso a empresas urbanizadoras que ofrecen este bien mediante sus servicios de construcción y entrega de las mismas. Siendo así que, tanto el gobierno y el sector privado, impulsan diferentes políticas para la permisología que requiere una empresa para poder construir.

Este crecimiento en la demanda de viviendas ha logrado que se active el sector construcción, existiendo 250 empresas constructoras afiliadas al CCN de las cuales 76 están activas, y el auge de empresas urbanizadoras que ofrecen el servicio de entrega de viviendas. Actualmente, en Nicaragua existen 35 urbanizadoras adscritas a CADUR, de las cuales algunas no solo fungen como agente productor de vivienda, definición establecida por primera vez por la Ley 677 y acuñada por INVUR mediante el Acuerdo Administrativo No. 00I-2014, sino también como constructoras; $y$ hay otras que se deciden por la contratación de una tercera empresa para la obtención de mano de obra que labore directamente en la construcción de dichas viviendas.

Por otro lado, según la Cámara de la Construcción de Nicaragua (2015) la construcción en el sector comercial ha tenido un crecimiento entre 2010 y 2014 debido a los nuevos proyectos de centro comerciales, no sólo en Managua sino en el resto del país. Es así que producto de la demanda ha surgido la necesidad de buscar otros medios de parte de las empresas desarrolladoras de proyectos habitacionales y comerciales para poder dar cumplimiento a dichos proyectos, por lo que requiere de otra empresa que dentro de su giro se encuentre la realización de obras civiles y que cuente con los medios técnicos y humanos para poder realizar la obra; donde nace la figura de la tercerización.

De acuerdo a la OIT (2009), la tercerización se produce cuando la empresa contrata con terceros, confiándole ciertas actividades o descentraliza su organización interna. Al momento de la celebración del contrato con una empresa, figura como un tercero respecto a las relaciones laborales de la empresa. En la actualidad esta figura es relacionada con el outsorcing, que no se encuentra regulada en nuestra legislación pero que se define como el "método mediante el cual las empresas se desprenden de alguna o algunas actividades que no forman parte de sus habilidades 
principales del giro del negocio, a favor de un tercero especializado en el ramo" (Castillo, 20 I0, p. 10); permitiendo de esta forma la concretización de esfuerzos a fin de obtener competitividad y resultados tangibles (Bolaños, pág. 4).

Pero, aun cuando se habla de outsorcing para las relaciones entre empresas, cuando una primera confía cierta actividad a una segunda, no significa que estamos ante la misma figura de la tercerización, ya que (según podremos ir viendo a través del presente estudio) son figuras distintas; y es que mientras en la tercerización la primera empresa delega una o varias actividades que se encuentran dentro del giro y en el mismo ramo de su actuación u objeto social. En cambio en el outsorcing dicha actividad no es parte de su objeto sino que se contrata un servicio por el simple hecho que no se encuentra dentro del giro o actividades esenciales de la organización de la empresa la realización de la misma.

\section{Análisis de Proyecto de Ley General de Regulación y Ordenamiento de la Tercerización, Subcontratación e Intermediación del Empleo}

En el año 2009 se presentó en la Asamblea Nacional de Nicaragua el Proyecto de "Ley General de Regulación y Ordenamiento de la Tercerización, Subcontratación e Intermediación del Empleo" "89, teniendo como una de las motivaciones el desarrollo de las prácticas laborales donde entran en juego dos empresas, una denominada principal y otra intermediaria o empleadora, en ciertos sectores como el agropecuario, bebidas y alimentos, puertos, aeropuertos, energía, comunicaciones e infraestructura, y por supuesto el de construcción.

Es significativo destacar que, para algunos tratadistas dicho desarrollo vinculado a la globalización conlleva al nacimiento de relaciones entre empresas de distintas ciudades, países o regiones, así como las relaciones entre empresas y Estado, que buscan eludir el cumplimiento de los derechos laborales y de seguridad social de sus trabajadores. Idea que comparte el Msc. Fernando Malespín, Experto en Derecho Laboral y Derecho Procesal Laboral, al afirmar que "mientras para los países que exportan globalización los standards laborales debe mantenerse, en los países que importamos globalización la receta es reducir los standards laborales" (2010, p. 6).

Aun cuando existan creyentes de que la globalización y el desarrollo de las prácticas empresariales conllevan a eludir el cumplimiento de los derechos laborales, principalmente en el sector construcción, no podemos negar que ya existen legislaciones que han creado normas adecuándolas al cumplimiento de dichos derechos, tal es el caso de Perú que posee la Ley que regula los servicios de tercerización (2008), o en el caso de España, Chile y Uruguay que se rigen bajo las figuras de la subcontratación e intermediación.

${ }^{89} \mathrm{La}$ iniciativa de ley fue presentada el 29 de abril de 2009. Actualmente se encuentra en la Comisión de Asuntos Laborales con código de iniciativa No. 20095852. Recuperado de http://www.asamblea.gob.ni/trabajo-legislativo/agenda-legislativa/ultimas-iniciativas-presentadas/ 
En cuanto a la presentación del Proyecto, su fundamento más importante radica en el perjuicio que, supuestamente, las figuras de tercerización, subcontratación e intermediación representan, como medio para evadir las obligaciones de los pasivos laborales y prestaciones sociales para los trabajadores. En este caso, la OIT menciona que la tercerización es “...utilizada para desmejorar condiciones de trabajo y/o para dificultar la acción colectiva de los trabajadores... aún cuando no hubieren sido premeditados" (OIT, p. I0).

Hasta esta parte, no podríamos definir o afirmar que estas nuevas figuras, y principalmente la tercerización, impliquen una precarización del empleo; es como lo establece, por otro lado la OIT, “...una descentralización productiva mediante la cual las empresas encargan a terceros una determinada o toda la operación de un proceso productivo..." (2009, p. 13); en el caso de Nicaragua, es falta de definición y regulación de la figura de tercerización, ya que como podemos ver, en el Art. 9 y en el Título VIII: Condiciones Especiales de Trabajo en el Capítulo VI del CT (1996), en los artículos 178, 179 y 180, la subcontratación está regulada desde 1996, principalmente en el ramo que nos interesa, la construcción.

Es, por tanto, que por primera crítica, podríamos formular que el Proyecto no viene a definir o regular la subcontratación como nueva forma de contratación laboral, inclusive en el ámbito de construcción es una figura que ha estado latente no sólo en la parte sustantiva de la ley sino en la práctica. Inclusive la Ley No. 6 I 8: Ley General de Higiene y Seguridad del Trabajo (2007) norma sobre esta figura basándose en el CT (1996) cuando establece en sus artículos que:

Art. 34: El empleador que usare el servicio de contratista y permitiese a estos la subcontratación, exigirá a ambos que estén inscritos en el registro correspondiente al Instituto Nicaragüense de Seguridad Social y que cumplan con sus obligaciones ante dicha institución...

Art. 35: El empleador, dueño o el representante legal del establecimiento principal exigirá a los contratistas y sub-contratistas el cumplimiento de las obligaciones legales en materia de prevención de riesgos laborales...

Siguiendo con el Proyecto de Ley General de Regulación y Ordenamiento de la Tercerización, Subcontratación e Intermediación del Empleo (2009), este se divide en once capítulos, del cual analizaremos lo más destacado en el estudio que nos interesa, es decir, la tercerización principalmente en el sector construcción ${ }^{90}$.

\footnotetext{
${ }^{90}$ Como parte del proceso de aprobación de una ley, y luego de la consulta realizada a los distintos sectores, el Consejo Superior de la Empresa Privada (COSEP) presentó otra versión del anteproyecto de la Ley titulándola "Ley de Regulación y Ordenamiento de la Tercerización" que, de acuerdo al Lic. Manuel Novoa, quien participó en la elaboración de la propuesta, la ley no tiene que regular la subcontratación ya que la misma se encuentra regulada, como anteriormente se observó, y que lo único que debe ser normado es la figura de la tercerización, por tal motivo dicha versión presentada consta únicamente de once artículos enfocados a la tercerización, obligaciones de las partes del contrato y la responsabilidad de las mismas.
} 
- Capítulo I: Disposiciones Generales

- Capítulo VII: De la tercerización del empleo en el sector construcción

Aunque, inicialmente, se establecen ciertas áreas donde estas formas de contratación han emergido, como los sectores agropecuarios, construcción, etc. el Art. I del Proyecto tiene como “...objeto, regular y ordenar las actividades de tercerización, subcontratación e intermediación del empleo en toda la República, y en todos los sectores de actividad económica, de producción y de servicios, tantos privados como públicos o estatales" (la cursiva es nuestra); inclusive las áreas que destacan en su regulación son las mismas en las que se fundamenta el Proyecto: Cap. VI: sector agrícola, Cap. VII: sector construcción, Cap. VIII: sector energía, comunicaciones, puertos y alcaldías, Cap. IX: sector bebidas y alimentos.

Como una segunda crítica, podemos mencionar que según se plantea en el párrafo anterior, aún cuando el Proyecto trata de regular las figuras de tercerización, subcontratación e intermediación, existe confusión en los términos y en los capítulos mencionados se refiere, solamente, a la figura de la tercerización en estos sectores.

Tomando en cuenta los objetivos del presente estudio, no abordaré todas las figuras ni todos los sectores que refiere el Proyecto, sino solamente la figura de la tercerización en el ámbito de la construcción.

\section{I Definición de tercerización}

La tercerización bajo la óptica del Proyecto, que es la modalidad laboral principal del presente estudio, se amplía la definición que fue presentada por la OIT abordada en el Capítulo I, como:

"Acción de contratación de empleo, bajo cualquier modalidad, por medio de la cual una persona jurídica o persona natural, contrata los servicios de otro empleador ya sea persona natural o persona jurídica, con la finalidad de obtener para sí, los servicios y actividades laborales de empleados y trabajadores de forma temporal o permanente, independientemente del vínculo jurídico que se establezca en virtud de tales contrataciones". (Proyecto, Art. 2, inc. a) (Cursiva es nuestra).

Entre todas las legislaciones, es importante destacar la definición realizada por la legislación peruana, de acuerdo al Reglamento (Decreto No. 006-2008-TR) que regula los servicios de tercerización:

Tercerización: Es una forma de organización empresarial por la que una empresa principal encarga o delega el desarrollo de una o más partes de su actividad principal a uno o más empresas tercerizadoras, que le proveen de obras o servicios vinculados o integrados a la misma (Art. I: Definiciones)

Es notorio como dicho reglamento define la tercerización enmarcado a la organización de una 
empresa, que según veremos en el transcurso del presente estudio es de gran importancia para establecer las razones por la cual una empresa terceriza una obra.

La definición que realiza el Reglamento (2008) señalado, se enmarca dentro de la realizada por la Ley de la materia en Perú, es decir la Ley No. 29245: Ley que regula los servicios de tercerización (2008), la cual dice:

Art. 2: Se entiende por tercerización la contratación de empresas para que desarrollen actividades especializadas u obras, siempre que aquellas asuman los servicios prestados por su cuenta y riesgo; sean responsables por los resultados de sus actividades y sus trabajadores estén bajo su exclusiva subordinación.

Dentro de esta definición que realiza la Ley podemos observar tres elementos característicos de la tercerización:

I. Desarrollo de las actividades u obras especializadas,

2. Responsabilidad propia por la obra y sus resultados, y

3. Subordinación exclusiva de sus trabajadores.

Estas características que se desprende de la Ley peruana las podemos encontrar en la legislación uruguaya en la Ley 1825I: Responsabilidad laboral en los procesos de descentralización empresarial con la diferencia que dicha legislación las inmersa en tres figuras: subcontratación (responsabilidad de la obra), intermediación (desarrollo de las actividades) y suministro de mano de obra (subordinación de trabajadores); por tanto no existe dentro de dicha legislación la figura propia de la tercerización.

Lo mismo que el párrafo anterior podemos encontrarlo en la legislación chilena y española, las características que se desprenden de la definición de la tercerización se vincula con la figura de la subcontratación; pero, a diferencia de estas legislaciones, también encontramos que la legislación peruana se encuentra avanzada en la definición y aplicación de la tercerización, y en caso que se llegase a aprobar en Nicaragua el Proyecto podremos dar un avance para la aplicación de esta nueva forma de contratación.

En cuanto a la definición del Proyecto y partiendo de la misma podemos establecer algunos puntos que se desglosan de la misma:

a) Modalidad de la contratación. Esto incluye a todas las personas definidas como trabajadores en el Art. 6 del CT que cita:

"Son trabajadores las personas naturales que en forma verbal o escrita, individual o colectiva, expresa o presunta, temporal o permanente se obligan con otra persona natural o jurídica denominada empleador a una relación de trabajo consistente en 
prestarle remuneración un servicio o ejecutar una obra material o intelectual bajo su dirección o subordinación directa o delegada".

En el sector construcción, podemos determinar que se refiere a todo el grupo de trabajadores que ayudan a la construcción de un proyecto urbanístico o de obras verticales, tales como arquitectos, ingenieros, albañiles, ayudantes de bodega, entre otros. El Convenio Colectivo (2007) define como trabajadores a las personas naturales que trabajan en este rubro, como son carpinteros, albañiles, armadores, similares y conexos.

Tal y como lo define la legislación peruana, este tipo de contratación "no restringe el ejercicio de los derechos individuales y colectivos de los trabajadores" (Ley 29245, Art. 2, parte infine). Lo cual se afianza con el Art. 2 de su Reglamento (2008) que instituye que "el ámbito de la Ley comprende a las empresas principales cuyos trabajadores estén sujetos al régimen laboral de la actividad privada".

b) La contratación de parte de una persona jurídica o natural. Dentro de las definiciones que refiere el Proyecto estas personas se identifican como "empresa usuaria principal", lo que contrasta con la definición de dicho término, ya que el Proyecto lo establece como:

“...la entidad jurídica que CONTRATA los servicios de otra persona jurídica o natural, para obtener a través de ella, los beneficios de la labor realizada por empleados o trabajadores cuyo esfuerzo laboral se aplica en el giro de su negocio" (Art. 2, inc. e).

Es decir, mientras la definición de tercerización amplía a las personas naturales el derecho de poder optar por los servicios de un tercero para la realización de un trabajo, la definición exacta de la empresa usuaria principal la excluye, dejando sólo este acto a las empresas jurídicas acorde a ley.

De acuerdo al Código Civil de Nicaragua (1904), las personas jurídicas son las asociaciones o corporaciones fundadas bajo un motivo público o particular donde sus relaciones civiles representan una individualidad jurídica (Art. 3). Dentro de este ámbito legal tenemos a las sociedades que se constituyen mediante un contrato para poner en común bienes o industrias para desarrollar un objeto social o un fin común comercial, lo que específicamente dicho código denomina sociedad como:

Art. 3175: El contrato en virtud del cual, los que pueden disponer libremente de sus bienes o industrias, ponen en común con otra u otras personas, esos bienes o industrias, o los unos y las otras juntamente con el fin de dividir entre sí el dominio de los bienes y las ganancias y pérdidas que con ellos se obtengan, o sólo las ganancias y pérdidas. 
Es decir, las sociedades se convierten en jurídicas una vez constituidas e inscritas debidamente acorde a ley.

Por otro lado, de acuerdo a la RAE empresa viene del italiano impresa definiéndola como la "unidad de organización dedicada a actividades industriales, mercantiles o de prestación de servicios con fines lucrativos" "'. El CT sigue la misma línea conceptual al establecer empresa como:

Art. 12: Se entiende por empresa la unidad económica de producción, distribución y comercialización de bienes y servicios. Se consideran como parte de la empresa los establecimientos, sucursales creadas para el crecimiento y extensión de sus actividades siempre que no constituyan una persona jurídica diferente.

Es decir, la empresa es la forma de organización económica de una sociedad. Igualmente, una persona puede constituir una empresa sin estar organizada como sociedad y por tanto mantiene su status de persona natural. El punto es saber si una persona natural tiene la capacidad de poder hacer frente a un contrato de tercerización mediante su organización como empresa ya que debe poseer todos los medios técnicos y económicos para poder brindar el servicio contratado.

Para la legislación chilena, empresa es "toda organización de medios personales, materiales e inmateriales, ordenados bajo la dirección de un empleador, para el logro de fines económicos, sociales, culturales o benéficos, dotada de una individualidad legal determinada" (CT, Art. 3, inc. c). Es así que consolidamos lo anteriormente dicho, la empresa es la única que podría fungir como empresa tercerizante ya que la misma, dentro de su concepto, se define como empleadora, la cual tiene bajo su cargo el grupo de trabajadores que requiere para el cumplimiento del servicio tercerizado contratado.

En el ámbito construcción dice el Proyecto:

Art.3I: El dueño de una obra o proyecto, podrá contratar a una Empresa Principal para que esta asuma la responsabilidad de la construcción hasta su conclusión completa. Esta será la Primera empresa contratista. La empresa Principal o primera empresa contratista, podrá a su vez, en un segundo nivel de contratación, sub contratar a empresas especializadas para segmentar la obra $\circ$ el proyecto $\circ$ a subcontratistas personas naturales...

Dicho artículo pone en relieve la delegación de la responsabilidad en la ejecución de una obra a otra empresa, ya que la principal puede no tener los recursos técnicos necesarios para la culminación del proyecto; lo que es una característica de la tercerización. Es así que, si una persona natural organizada como empresa no posee los medios necesarios y no se encuentra debidamente inscrita como empresa tercerizada, como lo veremos luego, no podrá hacer frente al contrato de tercerización.

\footnotetext{
${ }^{91}$ Recuperado de http://dle.rae.es/?id=EsuT8Fg .
} 
En cuanto al contrato a establecerse, existen dos tipos: el contrato entre las empresas, y el contrato entre la empresa constructora y sus trabajadores.

El contrato es el negocio jurídico bilateral generador de obligaciones, cuya finalidad radica en el intercambio de prestaciones de carácter patrimonial entre dos o más sujetos de derecho que ponen en común sus intereses (Herrera, J. \& Guzmán, J., 2014, pág. 32). El Código Civil de Nicaragua (1904) define el contrato como "un acuerdo de dos o más personas para constituir, regular o aclarar entre las mismas un vínculo jurídico (Art. 2435).

Por tanto, no hay duda que la figura del contrato es de suma importancia por la relación que nace entre las dos empresas; lo cual tomando en cuenta que ambas tienen como fin común la realización de un acto comercial considerándoles como comerciante, el contrato que nace entre ellas es de índole de comercio en base al Art. I CC: "Los contratos entre comerciantes se presumen siempre actos de comercio, salvo la prueba en contrario, y por consiguiente, estarán sujetos a las disposiciones de este".

En la Ley 29245 de Perú refiere a los contratos para la constitución de la tercerización, los cuales incluye los contratos de gerencia, contratos de obras, los contratos que tienen por objeto que un tercero se haga cargo de una parte integral del proceso productivo (Art. 3).

En materia de proyectos habitacionales, esta figura cobra gran importancia, no sólo al crear el vínculo jurídico entre urbanizador y cliente, para el ofrecimiento de una vivienda a cambio de una cantidad de dinero respecto a las garantías ofrecidas al cliente y que se derivan de la construcción de la misma; sino, entre la relación de una urbanizadora y una constructora no sólo al momento de pactarse los acuerdos y especificaciones que debe cumplirse para construir una vivienda, sino la relación que existe entre las dos empresas y la mano de obra directa en dicho servicio. Es por tanto, que nace la figura del contrato de trabajo entre la empresa que contrata directamente la mano de obra, ya sea la urbanizadora o la constructora.

Nuestro CT (1996) define el contrato de trabajo como "el convenio verbal o escrito entre un empleador y un trabajador, por el cual se establece entre ellos una relación laboral para ejecutar una obra o prestar personalmente un servicio" (Art. 19 parr.2).

Siguiendo con esta definición y tomando en cuenta que la empresa constructora es la que requiere de personal para poder realizar el trabajo contratado, nace así la relación laboral que cumple con las características propias de este tipo de contrato, como es la subordinación y la remuneración, de la empresa constructora y con la mano de obra requerida. El CT (1996) define la relación laboral de trabajo como “...cualquiera que sea la causa que le de origen, es la prestación de trabajo de una persona natural subordinada a un empleador mediante el pago de una remuneración” (Art. 19). 
En este punto es necesario mencionar que teniendo en cuenta la definición de empresa desarrolladora de proyectos habitacionales o para comercio que contrata bajo su giro comercial a otra empresa, no podríamos entonces definir que una persona natural pueda fungir como usuaria o empresa principal cuando no se encuentre organizada como empresa; ya que si una persona natural (no organizada) contrata los servicios de una empresa constructora para una obra menor y no para el cumplimiento de un giro comercial, estaríamos frente a un contrato de obra civil, un contrato de obras a destajo; que de acuerdo al Código Civil de Nicaragua (1904) el contrato de obras a destajo puede celebrarse encargándose el empresario por un precio determinado de la dirección de la obra, y poniendo los materiales, o simplemente poniendo el empresario sólo su trabajo o industria por un honorario fijo (Art. 3034).

Es decir, sería una obra aislada que la persona usuaria o principal realizaría sin que esto significare su giro comercial. Lo que lo diferencia de la tercerización, ya que uno de los principales objetivos es la delegación de una obra que realizaría a un tercero que tiene los medios o instrumentos para poder terminar dicha obra. Por lo tanto, estamos frente a una empresa que se dedique de forma constante al desarrollo de proyectos urbanísticos o de edificios, siendo su principal objeto social y por tanto para poder realizar dicho objetivo, debe acudir a otra empresa, debidamente constituida e inscrita, para delegarle ciertas funciones básicas para poder terminar de desarrollar su proyecto, en este caso, la construcción de las viviendas o del edificio.

c) La figura del empleador se encuentra latente en la figura de la tercerización, que de acuerdo al Art. 8 CT es "la persona natural o jurídica que contrata la prestación de servicios o la ejecución de una obra a cambio de una remuneración”.

De acuerdo al Convenio No. 100: Convenio sobre la igualdad de remuneración aprobado por la OIT en 195I, el término de remuneración comprende "el salario o sueldo ordinario, básico o mínimo y cualquier otro emolumento en dinero o en especie pagados por el empleador, directa o indirectamente, al trabajador, en concepto del empleo de este último" (Art. I, inc. a). En cuanto al CT (1996), mediante el Art. 8I define salario como "la retribución que paga el empleador al trabajador en virtud del contrato de trabajo o relación laboral".

Por tanto, en principio, toda persona, tanto natural que se encuentre organizada como empresa así como jurídica, puede ser empleador, siempre y cuando cuente con los medios para poder sufragar los gastos de los servicios que contrate y se encuentre debidamente inscrito como tal ante las instituciones requeridas.

El Código chileno (2016) no es la excepción en cuanto a la prestación de servicios, estableciéndolo como "la persona natural o jurídica que utiliza los servicios intelectuales o materiales de una o más personas en virtud de un contrato de trabajo" (Art. 3, inc. a).

En materia de la tercerización en los contratos de construcción, la persona que funge como empleador seria la empresa tercerizante, que de acuerdo al Art. 2, inc. f) del Proyecto es "la 
empresa o persona jurídica que contrata los servicios y trabajo de empleados y obreros, para ponerlos a disposición de una empresa usuaria principal”. La legislación española lo define como un intermediario, donde actúa mediante la contratación de trabajadores para la prestación de servicios a un tercero (Ley. No. 18.099, Art. I, inc. b). Es por tanto, que debe responsabilizarse ante este tercero para la entrega de lo encargado. En cambio, el Reglamento de la Ley 29245 (2008) de Perú, define perfectamente a la empresa tercerizadora como: "Empresa que lleva a cabo el servicio u obra contratado por la empresa principal, a través de sus propios trabajadores, quienes se encuentran bajo su exclusiva subordinación” (Art. I, Definiciones).

En este caso surge la tercera crítica al Proyecto, ya que paralelo a la empresa tercerizante, define al agente tercerizante como "la persona natural que contrata los servicios y trabajo de empleador y obreros para ponerlos de forma permanente o temporal al servicio de una empresa usuaria principal" (Art. 2, inc. f). Es decir, como anteriormente definimos tanto una sociedad como una persona natural organizada como empresa, pueden ser la empresa tercerizante, por lo tanto considero que esta figura no debería existir en dicho Proyecto.

De acuerdo a Díaz, Ureta \& Xalambri (2012), con la tercerización existe el control sobre la actividad contratada lo que la distingue del contrato comercial común, donde se cede el derecho de decisión para terminar el trabajo contratado. Es decir, como empresa tercerizante se tiene el control sobre las personas bajo su subordinación y necesarias para la realización del contrato de tercerización, debidamente inscrita como empleador y con la capacidad necesaria para el cumplimiento de los pasivos laborales.

Bajo esta misma óptica, es lo establecido por el Reglamento General en su Art. I, inc. b) al considerar empleador al que tenga bajo su cargo “...un número cualquiera de trabajadores, bajo su dependencia directa o indirecta, en virtud de una relación de trabaja o de servicio que nos vincule". Inclusive instruye que no se considerará empleador aquel que no se encuentra inscrito al Seguro Social; siendo uno de los requisitos de inscripción de cualquier empresa, no solamente estar debidamente constituida e inscrita ante el registro mercantil correspondiente, sino ante las direcciones fiscales, municipales y de seguridad en el país.

d) La temporalidad o permanencia del trabajo es importante para determinar que no importa el tiempo en que se pueda realizar el servicio ofrecido. La temporalidad del trabajo puede influir a la hora de poder determinar si se contrata una empresa tercerizante o mejor se busca tener dentro de la organización de la empresa a la persona a contratar para el trabajo permanente.

En este punto, podríamos establecer que para poder contratar de forma permanente los servicios de una persona, se utilizaría la figura de la intermediación para conseguir personal adecuado para la empresa, ya que dicha persona entraría en la planilla de la empresa para poder cumplir de forma constante el trabajo designado. 


\subsection{Deberes de las empresas tercerizantes}

Una de las novedades del Proyecto es la inclusión de requisitos que deben cumplirse para poder ser empresa tercerizante y para poder contratar mediante esta figura de contratación laboral, tales como que las empresas que deseen fungir como empresas tercerizantes deberán inscribirse en el Registro Nacional de Empresas; sin menoscabo de los requisitos de constitución e inscripción que le permitan a las empresas mercantiles obtener su personería jurídica, o a las personas naturales estar inscritos como comerciantes.

Este requerimiento parece haberse tomado de lo regulado por la Ley 29245 (2008) de Perú ya que, en la misma, se indica el deber de registrarse ante un "Registro Nacional de Empresas Tercerizadoras" que estará a cargo de la Autoridad Administrativa de Trabajo (Art. 8).

Art.3. Ninguna empresa TERCERIZANTE, ... podrán iniciar ni desarrollar sus actividades sin estar previamente inscritas en el REGISTRO NACIONAL DE EMPRESAS dedicadas a estas actividades, a cargo del Ministerio del Trabajo, quién abrirá el mismo para tales fines en un plazo no mayor de cuarenta días una vez que entre en vigencia la presente ley. El Ministerio del Trabajo por medio de una resolución ministerial establecerá los requisitos formales para la inscripción correspondiente

Art.4. Cuando una empresa Tercerizante... realice sus actividades en un radio geográfico limitado, se inscribirá en la correspondiente delegación departamental del Ministerio del Trabajo, observando los mismos requisitos que para tales efectos sean dispuestos por esta entidad estatal.

En Perú, el plazo para inscribirse como empresa tercerizante es de treinta días hábiles desde su constitución, lo que da a entender que una empresa al constituirse previamente debió establecerse que se dedicaría a ofrecer este servicio, lo que la diferencia, a mi parecer, de Nicaragua en la libertad que tienen las empresas de poder desarrollarse y que si en el camino desea ofrecer estos servicios pueda libremente inscribirse como tal.

Las empresas tercerizantes deban cumplir con ciertos requisitos para poder trabajar como tal. Tal y como lo sigue plasmando el Proyecto en el Art. 8:

Las empresas tercerizantes para ser reconocidas e inscritas como tales, deben cumplir con los siguientes requisitos:

a) Haberse constituido bajo las modalidades que la ley establece para la conformación de empresas en el país,

b) Contar con patrimonio propio.

c) Contar con una representación legal de personeros que sean ciudadanos nicaragüenses, o extranjeros con residencia otorgada, bajo las reglas de Migración y extranjería. 
d) Contar con domicilio legal en Nicaragua.

Anteriormente, hemos definido que las empresas tercerizantes, sean personas jurídicas o personas naturales organizadas como empresas, se definen en base al CC (2014) como comerciantes, y como tal deben cumplir ciertos requisitos de inscripción; sin tomar en cuenta que las sociedades mercantiles deben cumplir con más parámetros para su funcionamiento, que las personas naturales organizadas como empresas. Por tanto, este artículo simplemente recopila los requisitos previamente establecidos en la inscripción como comerciante, ante la DGI bajo el régimen jurídico o como régimen general, Alcaldía Municipal como contribuyente municipal, e INSS bajo régimen patronal. Sin olvidar que con la aprobación del Proyecto se crearía un nuevo registro especial a cargo del MITRAB para las empresas que deseen fungir como tercerizantes.

\subsection{Tercerización entre empresas relacionadas}

Cuando las modalidades de contratación de tercerización o subcontratación se establezcan entre dos empresas relacionadas, para todos los efectos legales vinculados a la responsabilidad por derechos y pasivos laborales, la empresa usuaria principal será considerada como el EMPLEADOR de los obreros y empleados contratados bajo tales condiciones. Cuando una empresa tercerizante o subcontratista provee personal a un solo empleador o empresa usuaria principal se presumirá automáticamente que se trata de empresas relacionadas (Proyecto, Art. 5).

Cuando la ley vincula a dos empresas relacionadas, se refiere a que ambas empresas pertenecen a un mismo grupo empresarial o accionario, no al rubro ya que como podemos establecer la empresa principal y la constructora pertenecen a actividades económicas diferentes como, por ejemplo, en las actividades inmobiliarias encontramos la compra, venta, alquiler y explotación de bienes inmuebles, tales como edificios de apartamentos, viviendas y edificios no residenciales, urbanización y venta de terrenos. Por otro lado, la clasificación en el sector construcción incluye construcción de edificios completos, obras de ingeniería civil. Entonces, la empresa desarrolladora de proyectos habitacionales o comerciales requiere de los servicios ofrecidos por la constructora, sin que esto signifique que se encuentran dentro del mismo giro comercial, por tanto, ambas empresas pertenecen a distintas áreas comerciales.

Es así que surge una cuarta crítica al Proyecto en cuanto a que si dos empresas pertenecen a un mismo grupo empresarial existirá responsabilidad solidaria, ya que como establecimos anteriormente y de acuerdo al clasificador de las actividades comerciales, ambas empresas tienen distintos rubros, aunque requieran una de la otra para un fin común: desarrollo de un proyecto mediante la construcción de la obra. Es por tanto que, perfectamente puede existir una tercerización sin que esto signifique una subcontratación o intermediación y pueda considerarse como empleadora a la empresa principal. 
También, al decir que se considerará como empleador a la empresa usuaria, aún cuando la empresa tercerizante se encuentre debidamente y por ley, inscrita y autorizada, se volvería inatractivo para las personas de poder constituir otras empresas que puedan dar respuesta a sus necesidades, o en el caso que el objeto social en las que se encuentra constituida la primera empresa no sea dentro del rubro que requiera realizar u obtener el servicio, todo para que pueda nacer una relación de tercerización entre las empresas.

Ahora, si nos referimos a que dicha empresa sólo sea creada para ser contratada como empresa tercerizante única y exclusivamente a la empresa usuaria o principal, aún cuando la doctrina considere lo contrario, a nivel personal considero que este tipo de relación de las empresas no puede considerarse tampoco como una forma de precarizar las relaciones laborales; sino que simplemente se piensa ampliar la gama de servicios y obras que un grupo de inversionista busca realizar dentro de la competitividad del rubro.

Aunque bien es cierto que la tercerización y subcontratación son dos figuras diferentes, dentro del ramo de la construcción podemos comprobar que en la práctica muy bien pueden subsistir sin que esto signifique una mezcla de los derechos y deberes de las empresas en un contrato de tercerización. En este caso, el Art. 32 del Proyecto establece:

En el sector de la construcción, las empresas podrán subcontratar parte o la totalidad de las obras especiales, siempre y cuando corresponda a partes distintas y separadas. Por lo tanto no podrán ser subcontratadas obras de oficios básicos de carpintería, albañilería, armaduría y similares establecidas en el Convenio colectivo de la Construcción, pudiéndose subcontratar las actividades que impliquen una labor de especialización dentro de las obras de electricidad, fontanería, plomería, pintura, montaje y desmontaje de estructura, únicamente. En todo caso, del total de trabajadores aplicados a un proyecto u obra, un mínimo del $20 \%$ serán trabajadores propios de la Empresa Contratista Principal.

De este artículo se desprende lo siguiente:

a) No existe una separación de tercerización y subcontratación al momento de definir las figuras, para que no exista confusión al momento de establecer hasta donde el contrato de tercerización permite la subcontratación.

b) Las obras básicas de la construcción que, más que todo, se refiere a la parte estructural de una obra, no podrán ser subcontratada, deben ser parte esencial de la tercerización; lo que es perfectamente aceptable ya que como mencionábamos si la tercerización es delegar una función necesaria de la obra para el desarrollo del proyecto de la empresa principal, lo primordial es la estructura del mismo.

c) Dentro de la figura de la tercerización perfectamente puede surgir la subcontratación, cuando se requiera los servicios de obras menores o de detalle, lo que no significa que la empresa principal pase a ser empleador de estas personas por el hecho de que realicen un trabajo menor en la obra, simplemente estamos 
ante una relación biunivoca donde solo surge una subcontratación por un servicio específico.

d) En cuanto al mínimo de trabajadores, se debe especificar bien si es la empresa principal, es decir la Tercerizante, o la empresa empleadora que ejecuta la obra delegada. Nuevamente, es necesario diferenciar entre las dos figuras para que pueda quedar claro al momento de establecer en el contrato de obra de construcción tercerizado.

El Art. 8 del Proyecto, Capítulo II: De las Empresas Tercerizantes, establece los requisitos para la inscripción de una empresa tercerizante:

a) Haberse constituido bajo las modalidades que la ley establece para la conformación de empresas en el país.

b) Contar con patrimonio propio.

c) Contar con una representación legal de personeros que sean ciudadanos nicaragüenses, o extranjeros con residencia otorgada, bajo las reglas de Migración y extranjería.

d) Contar con domicilio legal en Nicaragua.

Asimismo, y como parte cumbre de estos requisitos, en el Art. 9 del Proyecto manda a que la empresa tercerizante debe presentar “... una fianza equivalente al $60 \%$ de su planilla proyectada para los primeros tres años de operaciones... y estará destinada únicamente para prever la eventualidad del pago de los pasivos laborales de los trabajadores contratados bajo esta modalidad por la empresa". Por tanto, si la empresa tercerizante debe cumplir con el requisito de estar constituido e inscrito legalmente, y sobre todo presentar dicha fianza, significa que estos requisitos constituyen una seguridad para que los pasivos laborales no sean violentados al momento de su cumplimiento. Y por ende, esta empresa perfectamente puede hacer frente a una demanda por dichos pasivos sin que esto incluya a la empresa usuaria.

En cuanto a la demanda ante una situación de incumplimiento de las obligaciones laborales, ya el Código Procesal del Trabajo y de la Seguridad Social de Nicaragua (2012) actual establece en su Art. 8I que:

En la interposición de la demanda en el caso del empleo tercerizado, el actor podrá solicitar a la autoridad judicial, la comparecencia de la empresa principal usuaria de ese servicio a fin de determinar en la sentencia la existencia de responsabilidad subsidiaria en los términos formulador por las leyes de la materia.

Con este artículo se observa que la ley le impone una responsabilidad subsidiaria a la empresa usuaria, es decir, que en caso que la empresa tercerizante no pueda cumplir sus obligaciones laborales, ya sea por decisión o por quiebra o insolvencia, la empresa principal deberá hacer frente a las obligaciones laborales. Pero, si una empresa desarrolladora contrata una empresa constructora que cumple con todos los requisitos de ley para poder operar como tal, y sobre 
todo, está debidamente inscrita ante el Registro Nacional de Empresas, así como la licencia de apertura emitida por el MITRAB y la licencia emitida por el MTI para poder operar como tercerizante en la rama de la construcción, debe asumir todas las responsabilidades y obligaciones laborales, seguridad social entre otras, así como posibles demandas por parte de sus trabajadores, sin que esto influya o perjudique todo contrato comercial de tercerización que tenga con otras empresas. Por tanto, no cabría la responsabilidad subsidiaria ni solidaria para la empresa usuaria o principal, siendo su único deber el establecer al inicio de la relación contractual el cumplimiento de todos los requisitos que se le imponen a la empresa tercerizante de poder actuar de esa forma.

Siguiendo la línea anterior, el Art. 35 del Proyecto dice:

Todas las empresas que operen como Contratistas principales o como Empresas Subcontratadas para el segundo nivel, con alguna actividad de especialización, deberán contar con EQUIPOS Y MEDIOS PROPIOS DE CONSTRUCCION y capital suficiente para responder por pasivos laborales. Igualmente deberán estar debidamente inscritos ante las autoridades del MTI, Alcaldías, D.G.I., e INSS, según la reglamentación pertinente $y$ en el Registro de empresas subcontratistas y tercerizadoras del Ministerio del Trabajo.

Por tanto, nuevamente retomamos el hecho de que si la empresa a quien se le delega la obra de construcción en un contrato de tercerización, debe cumplir con las inscripciones debidas y la fianza, quiere decir que dicha empresa constructora podrá hacer frente a la obra contando con sus equipos y medios propios para realizarla, lo que es un requisito esencial para que pueda hacer frente al contrato de tercerización suscrito. Por tanto, estamos frente a una empresa que definitivamente no delegaría su función de empleadora a la empresa principal y no significaría una obligación solidaria ni subsidiaria al momento de pagar dichas obligaciones laborales, como lo pretende establecer el Art. 33 del Proyecto, queriendo delegar dicha obligación sin tomar en cuenta los requisitos previamente establecidos y cumplidos para la empresa empleadora; por lo que la principal obligación, como indicábamos anteriormente, de la empresa usuaria o principal es la de revisar que la empresa con la cual está contratando cumpla con todos los requisitos establecidos para ser tercerizante y que, por ende, este cumpliendo con las obligaciones laborales y de seguridad social.

Por otro lado, y siguiendo con la crítica, se cierra la posibilidad a empresas pequeñas de poder inscribirse como tercerizante en un rubro grande, como es el de construcción, ya que debe cumplir con el requisito de tener más de una empresa usuaria porque si no podría estar señalada como una empresa relacionada como lo estipula la parte infine del Art. 5 del Proyecto. Principalmente, cuando la fianza puede ser muy alta ya que existen empresas pequeñas que pueden asumir con poco personal la realización de una obra. Esta disposición beneficia únicamente a las grandes empresas constructoras y perjudica a las pequeñas del mismo ramo ya que no podrán licitar en proyectos de construcción. 


\subsection{Responsabilidad Solidaria}

Art. 6. Todas las empresas tercerizantes o subcontratistas utilizarán CONTRATOS ESCRITOS con el personal que labora para ellas. El texto del contrato que sirva como formato común a todos los contratados, deberá ser aprobado oportunamente por la Inspectoría Departamental del Trabajo más cercana al sitio en que desarrolla sus actividades, o por la Inspectoría General si realiza sus labores en todo el país. La omisión del contrato escrito autorizado por el MITRAB, genera de forma automática la Solidaridad Responsable entre la empresa tercerizante o subcontratista y las empresas usuarias principales para las cuales opera. (Proyecto)

Ante la falta de presentación de este contrato, la empresa principal se convierte en solidaria al momento del cumplimiento de las prestaciones laborales. En este caso, se podría mejorar tomando en cuenta este requisito dentro del trámite de inscripción de la empresa tercerizante y no como un trámite aparte, donde se revisaría si cumplen con los requisitos mencionados en el Art. 20 CT (1996) que incluyen:

a) Lugar y fecha de la celebración;

b) La identificación y domicilio de las partes y en su caso, el nombre y apellido del representante legal de la entidad empleadora,

c) Descripción del trabajo y lugar o lugares donde deba realizarse;

d) La duración diaria y semanal de la jornada y si esta es diurna, mixta o nocturna;

e) Indicación de si el contrato es por tiempo determinado o de duración indefinida;

f) La cuantía de la remuneración, su forma, períodos y lugar de pago, y si se conviene por unidad de tiempo, por unidad de obra, por tarea o a destajo, por comisión o participación en los cobros o ventas o en las utilidades y cualquier otro complemento salarial, así como la forma de cálculo en la remuneración;

g) La firma de los otorgantes o su representante legal, o impresión digital o ruego de los que no sepan o no puedan firmar, en presencia de dos testigos.

Dicho requisito se afianza en el Art. 33 del Proyecto:

Cuando los trabajadores directos ubicados en la cadena final de la subcontratación no perciban legalmente lo que les corresponda en materia de salarios, prestaciones sociales, indemnizaciones, cobertura de afiliación al INSS, y derechos contenidos en el Convenio Colectivo de la Construcción y la legislación ordinaria, todos los componentes anteriores a él, en la cadena de la subcontratación serán SOLIDARIAMENTE RESPONSABLES de ese pago, incluyendo al dueño de la obra. El trabajador tendrá la opción de demandar a cualquiera de ellos, 0 a todos simultáneamente.

Lo establecido en el artículo referido es una situación a considerarse extrema y poco práctica, además promueve el incumplimiento de las obligaciones del empleador directo de los 
trabajadores, ya que los mismos podrían demandar a la empresa usuaria o principal; lo que conllevaría a que únicamente se contrataría con empresas constructoras grandes para no correr riesgos, por lo que no beneficia a las pequeñas o nuevas empresas.

Siguiendo con los argumentos expuestos con anterioridad, si uno de los requisitos sine qua non es la inscripción de la empresa constructora y sobre todo llenar los requisitos como la fianza, significa que la empresa tercerizante puede hacer frente a sus pasivos laborales. Es más, el Proyecto manda a que dentro del presupuesto presentado, se tomen en cuenta los pasivos laborales que deben cumplirse con el personal que estará directamente relacionado con la construcción:

Art. 34: En el presupuesto general de una obra de construcción o proyecto, SIEMPRE serán incluidos los componentes relacionados con el pago de prestaciones sociales, indemnizaciones, cuotas al INSS, Ley 618, y todos los beneficios reconocidos en el convenio colectivo de la construcción. Esta disposición será exigible tanto en obras privadas, mixtas, así como en proyectos del sector público o estatal, nacionales o extranjeras y a personas naturales o jurídicas que construyan en cualquier lugar del territorio nacional.

Ahora, si una de las características de la tercerización es la contratación de una empleadora, es decir, una empresa que tiene bajo su organización una planilla con trabajadores constantes y que remuneran por los trabajos que realizan, la cual puede hacer una obra, en este caso una construcción porque está dentro de su giro comercial o del negocio, y que toda relación que pueda tener con la empresa usuaria es más que todo el cumplimiento y entrega de una obra urbanística o de edificios. Por tanto, el hacer solidaria a la empresa principal sería estarle pasando las responsabilidades de otra empresa que perfectamente puede hacer frente a sus deberes por todo lo anteriormente expuesto. Inclusive existe una protección al momento de cumplir con el Art. 34 desde la oferta misma de la obra a realizarse, siendo así que la empresa empleadora podrá hacer frente de sus obligaciones sin que requiera de una solidaridad de parte de la empresa principal, y ésta estaría exenta de dicha obligación porque desde el cumplimiento de los pagos sujetos del contrato estaría haciendo frente a los derechos de los trabajadores.

También debemos recordar que en caso de disolución de una empresa, lo primero que se cumple son con las deudas de la empresa, en este caso con los pasivos laborales (CC, Art. 280), es decir, si la misma empresa tercerizante no puede eludir el cumplimiento de los pasivos laborales, inclusive en su liquidación, la empresa usuaria no debería considerarse solidariamente responsable de dicha empresa.

Actualmente, el Código Procesal del Trabajo (2012) ya instituye la responsabilidad subsidiaria en caso del empleo tercerizado al establecer: 
Art. 8I: En la interposición de la demanda en el caso del empleo tercerizado, el actor podrá solicitar a la autoridad judicial, la comparecencia de la empresa principal usuaria de ese servicio a fin de determinar en la sentencia la existencia de responsabilidad subsidiaria en los términos formulados por las leyes de la materia.

Es decir, estamos ante un presupuesto procesal donde se determinará los casos en que pueda existir la responsabilidad subsidiaria, no necesariamente significa que desde el inicio de la relación triangular exista, ya que dicha responsabilidad nace cuando el contratista 0 subcontratista no cumpla con sus obligaciones laborales, lo que conlleva a que el trabajador primeramente demanda a su empleador directo y en caso que este no responda podrá demandar al empleador principal.

Pero, como hemos señalado anteriormente existen presupuestos que determinan desde el inicio de la relación tercerizada el cumplimiento de los deberes del empleador, en este caso, el empleador directo es decir de la empresa tercerizante. Igualmente, podemos observar que en la Ley $6 / 8$ (2007) se determinan otras responsabilidades, por un lado establece en su Art. 18, inc. 9 la obligación del empleador de "exigir a los contratistas y sub-contratistas el cumplimiento de las obligaciones legales en materia de higiene y seguridad del trabajo. En caso contrario se hace responsable solidario por los daños que se produzcan por el incumplimiento de esta obligación". Es decir, otro requisito que puede determinarse al momento de contratar con una empresa tercerizante y que la principal debe tomar en cuenta es el cumplimiento de estas obligaciones.

Por otro lado, la misma Ley $6 / 8$ (2007) establece otras obligaciones de las empresas contratistas y sub-contratistas importantes y relacionadas con el cumplimiento de los deberes laborales y el derecho que tiene la empresa principal de exigirlas, como son:

Art. 34: El empleador que usare el servicio de contratista y permitiese a estos la subcontratación, exigirá a ambos que estén inscritos en el registro correspondiente al Instituto Nicaragüense de Seguridad Social y que cumplan con sus obligaciones ante dicha institución. En caso de incumplimiento, el empleador será solidariamente responsable de las obligaciones que dicho contratista o subcontratista tienen con sus trabajadores de conformidad con el Código de Trabajo y la Ley de Seguridad Social.

Art. 35: El empleador, dueño o el representante legal del establecimiento principal exigirá a los contratistas y sub-contratistas el cumplimiento de las obligaciones legales en materia de prevención de riesgos laborales, en caso contrario responderá solidariamente por los daños, perjuicios ocasionados a los trabajadores.

Si nos referimos a la responsabilidad solidaria que se establece a la luz de estos artículos, significa que el trabajador podrá demandar conjuntamente a ambas empresas, es decir a su empleador directo y a la empresa principal. Pero, igualmente dichos artículos dan la 
oportunidad a que la empresa principal pueda exigir a su empresa tercerizante de que cumpla con todas las previsiones legales en materia legal para que cumpla en un futuro con las mismas.

En el caso del presente estudio, como indicaba anteriormente, existen en las diferentes normas legales actuales $y$ en el Proyecto requisitos que debe cumplir la empresa tercerizante de forma que no exista responsabilidad solidaria ni subsidiaria, ya que la empresa principal ha proveído desde el inicio del contrato que la empresa contratada cumple con todas estas normas.

\section{Régimen de las empresas partes y rol de las instituciones públicas}

Como hemos visto anteriormente, en los contratos tercerizados en el ámbito de construcción nos encontramos en una relación triangular donde emergen las figuras de la empresa usuaria o principal, empresa tercerizante y los trabajadores que realizan las obras directamente. La OIT (2009) utiliza esta expresión de relaciones triangulares cuando hace referencia a ejecución de obras, prestación de servicios y suministro de personal mediante la contratación mercantil.

Asimismo, encontramos que en dichas relaciones juegan un papel importante las instituciones estatales cuyo único fin es el de fiscalizar que se cumplan con las obligaciones laborales, de seguridad social, y de higiene y seguridad, tales como el MITRAB y el INSS. Esto, sin obviar al INVUR en su papel de rector en el ámbito de construcción de las viviendas.

De acuerdo a Bruno Vidaurre, Director de la CCN, la Ley General de Regulación y Ordenamiento de la Tercerización, Subcontratación e Intermediación ha sido un tema latente dentro del gremio para poder establecer las figuras contractuales, aunque no niega que detrás de la misma existen muchos intereses de parte del Estado, empresas privadas, organismos internacionales y sindicatos que no se ponen de acuerdo para que pueda prosperar su aprobación.

Asimismo explica que bajo el tema del principio in dubio pro operario, si el contratista no se encuentra debidamente asesorado a la hora de contratar con otras empresas, a la menor oportunidad de algún reclamo si existen vacíos dentro del mismo contrato, la empresa siempre responderá en toda la cadena de la contratación.

\section{I Empresa usuaria o principal}

La figura de la empresa usuaria o principal surge con el Proyecto, en su Art. 2, inc. e). Luego, el mismo Proyecto en el Art. 3I, Capítulo VII, confunde la figura de la empresa usuaria o principal con la de la empresa contratista que figura en la subcontratación. Dice el artículo:

El dueño de una obra o proyecto, podrá contratar a una Empresa Principal para que esta asuma la responsabilidad de la construcción hasta su conclusión completa. Esta será la Primera empresa contratista. La empresa Principal o primera empresa contratista, podrá a su vez, en un segundo nivel de contratación, sub contratar a empresas especializadas para segmentar la obra o el proyecto a subcontratistas 
personas naturales. Las empresas subcontratadas en el segundo nivel y los subcontratistas personas naturales, contratarán solamente trabajadores, DIRECTOS y no podrán a su vez, subcontratar con empresas o personas, las obras o tareas contratadas por ellas.

Ambos artículos difieren, mientras en el Art. 2, la empresa usuaria o principal es la dueña de la obra a desarrollarse, en cambio en el Art. 3I, dicha empresa es la contratada para realizar la obra y subcontratar para poder dar respuesta a la contratación realizada.

La Ley 29245 (2008) de Perú define a la empresa principal como la encargada o la que delega "el desarrollo de una o más partes de su actividad principal a una empresa tercerizadora" (Art. I: Definiciones). Es decir, en dicha legislación la empresa principal no solamente pude delegar e desarrollo de una obra sino que también puede dirigirla.

En Nicaragua, al momento de contratar surge la primera y principal obligación en la relación de tercerización entre la empresa usuaria o principal y la constructora o tercerizante, que es la de revisar si la empresa con la que contratará cumple con todos los requisitos establecidos en el Proyecto para poder consignarlos en dichos contratos, así de esta forma la empresa usuaria o principal dejaría de tener responsabilidad ante cualquier situación de incumplimiento de las obligaciones sociales.

Es así que el Art. 10 del Proyecto establece lo que debe consignar dichos contratos, tales como:

a) El deber de las empresas tercerizantes de inscribir en el seguro social a los trabajadores contratados bajo esta modalidad.

b) El deber de las empresas tercerizantes de asumir el pago efectivo de todos los derechos y pasivos laborales consignados en el Código del Trabajo.

c) El deber de las empresas tercerizantes de respetar a plenitud el derecho de los trabajadores y empleados contratados bajo esta modalidad a organizarse sindicalmente, incluyendo a los trabajadores temporales, que podrán figurar como afiliados al sindicato durante el tiempo que dure su contratación.

d) La obligación y responsabilidad de las empresas tercerizantes de garantizar a sus trabajadores $y$ empleados las MISMAS CONDICIONES Y BENEFICIOS LABORALES, consignados para los trabajadores y empleados de las empresas usuarias principales, ya sea en la convención colectiva, en acuerdos bilaterales, o en el marco de las políticas de personas de tales empresas contratantes.

\subsection{Empresa constructora o tercerizante}

Como referí anteriormente, el contrato de tercerización se pacta ya sea con una persona jurídica, es decir, empresa tercerizante, o con una persona natural constituida como empresa, denominada agente tercerizante. Asimismo, dicha persona natural o jurídica puede contratar 
a otra persona natural o jurídica cuando dentro de su organización no posea cierta mano de obra de trabajos especializados, es decir puede ser a la vez subcontratista.

Esta facultad de poder ser subcontratista se determina en el Art. 32 del Proyecto que cita:

"En el sector de la construcción, las empresas podrán subcontratar parte o la totalidad de las obras especiales, siempre y cuando corresponda a partes distintas y separadas... pudiéndose subcontratar las actividades que impliquen una labor de especialización dentro de las obras de electricidad, fontanería, plomería, pintura, montaje y desmontaje de estructura, únicamente..."

Igualmente, la Ley 29245 (2008) de Perú da la potestad a la empresa tercerizante de poder subcontratar, aunque el mismo no establece taxativamente que tipo de trabajos puede subcontratar, como lo establece el Proyecto en nuestra legislación.

De acuerdo a la OIT, si el contratista no cuenta con un aparato productivo propio especializado y de suficiente entidad, limitándose a proporcionar trabajadores a la empresa principal, se está ante una mera intermediación o marchandage ${ }^{92}$ (mercado de mano de obra) (OIT, p.24). Es decir, la OIT lo equipara a un simple suministrador de personas, siempre y cuando la empresa no cuente con una organización de forma tal que pueda hacerse cargo de la obra.

Si nos referimos a la definición de empleador que hace el Convenio de la Construcción (2007) como "todas las personas naturales o jurídicas que contratan mano de obra obrera (carpinteros, albañiles, armadores, similares y conexos)" (Convenio, Definiciones, inc. A); entonces podemos determinar que la empresa constructora o tercerizante es la que funge como empleador en la relación triangulada que nace entre la empresa usuaria o principal, la empresa constructora o tercerizante y los trabajadores, ya que esta es la que debe buscar o tener bajo su organización a todo este personal que requiere para cumplir con la obra contratada.

En cuanto a las obligaciones que estas empresas deben tener dentro del gremio de la construcción con sus trabajadores, el mismo Convenio en su Clausula 10 cita algunas como "garantizar a todos los trabajadores de la construcción que estén asegurados para que gocen de atención médica de calidad en las empresas médicas previsionales y contratadas por el INSS" (inc. h).

\footnotetext{
${ }^{92}$ Nombre tomado del francés que significa negociación, regateo.
} 


\subsection{Trabajadores o mano de obra}

El Convenio de la Construcción (2007) define a los trabajadores en su gremio como "todas las personas naturales (carpinteros, albañiles, armadores, similares y conexos)" (Definiciones, inc. b).

Respecto al Proyecto, nuevamente hace énfasis en la facultad que tienen los trabajadores de gozar a plenitud de los derechos laborales de sindicalización y de negociación de convenios colectivos, y todas las opciones colectivas consignadas en la ley y los convenios de la OIT (Art. 37).

En la relación triangulada que nace en los contratos de tercerización, los trabajadores son considerados como los más vulnerables, principalmente cuando no existe la verdadera figura de quién es el empleador. Esta confusión podría ser en el caso de Perú, cuando en su Ley 29245 (2008) establece que la empresa tercerizante puede trasladar personal de su administración al centro de operaciones de la empresa principal; es decir, si la empresa tercerizante realiza la obra encomendada en un lugar del dominio de la principal, definitivamente se está trabajando en el lugar de esta.

\subsection{El rol del Ministerio de Trabajo}

Para el MITRAB la tercerización no es una figura nueva en el ámbito de la construcción, ya que se han encontrado con ella por un tiempo, para precarizar las condiciones de los trabajadores y evitar el cumplimiento de las normas laborales; aunque es importante destacar que debido a la falta de definición y regulación de la figura, la misma es confundida y tratada como la subcontratación, a como se ha presentado en dicha institución pública. Es así que la principal base para equiparar a la empresa usuaria o principal como un empleador directo es el Art. 9 CT (1996) cuando dice que "tienen carácter de empleadores los contratistas, subcontratistas y demás empresas que comtrarán a trabajadores para la ejecución de trabajos..."

De acuerdo a entrevista realizada a inspector laboral del MITRAB ${ }^{93}$, se han encontrado en situaciones que los mismos trabajadores no saben específicamente quien es su empleador, y es ahí donde entra en juego su rol fiscalizador y garante, conllevándolos a averiguar quién es el dueño de la obra, y recayendo sobre este el papel de empleador y las obligaciones laborales.

Dicha función de poder inspeccionar la delega la Ley No. 664: Ley General de Inspección del Trabajo (2008), la cual estatuye en su Art. 21 que "corresponde a los Inspectores del Trabajo, el ejercicio de la función inspectiva y de aquellas otras competencias que le faculte el

\footnotetext{
${ }^{93}$ Lic. Eduardo Sarria, Inspector del Trabajo de Managua en el MITRAB. Entrevista realizada el día 08 de junio de 2016.
} 
ordenamiento jurídico laboral”. Asimismo, el Art. 27 de esta misma ley, faculta a los Inspectores a:

a) Exigir el cumplimiento de las normas legales, reglamentarias, convencionales y condiciones contractuales en material laboral...

b) Exigir la presencia del empresario o de sus representantes y encargados, de los trabajadores y de cualquier sujeto incluido en su ámbito de actuación...

c) Requerir en el centro de trabajo la documentación y los libros de la empresa con relevancia en la verificación del cumplimiento de la legislación laboral...

d) Cuando se demuestre que el empleador está evadiendo injustificadamente sus responsabilidades con los trabajadores, el Inspector del Trabajo, con el Acta de Inspección podrá solicitar a la autoridad judicial que se dicten medidas cautelares...

En el sector de los empleadores o tercerizantes en la construcción, el MITRAB velará y será garante para que se cumplan en su totalidad las condiciones referentes a los subcontratistas de obras y tiene las facultades para pronunciarse sobre quién llena los requisitos para ser subcontratista de obras y quien no los llena.

De acuerdo al Delegado Específico del MITRAB, su función de inspección empieza cuando existe una presunción de relación laboral; en dichas inspecciones toman en cuenta el tiempo de la obra, participación de la obra, requieren la documentación de la empresa para poder determinar con precisión quien es el empleador. En caso de inconsistencias o de no encontrarse alguna persona que pueda representar al empleador le establecen un plazo prudencial para que se presente ante las oficinas del MITRAB y presente toda la documentación necesaria: constitución de la empresa, contrato de trabajo, planilla, etc., todo basado en la Ley General de Inspección del Trabajo (2008).

Para el MITRAB es obvia la necesidad de determinar quién es el que verdaderamente funge como empleador para el cumplimiento de las obligaciones laborales, principalmente en las relaciones de subcontratación, figura latente que sigue siendo confundida con la tercerización. Ya que para ellos el dueño de la obra sigue siendo el empleador.

\subsection{El rol del Instituto Nicaragüense de Seguridad Social}

Para el INSS esa dependencia indirecta que se establece en el Art. I del Reglamento General (1982) hace a una empresa usuaria o principal una empleadora, ya que, así como el MITRAB, en la práctica se confunde a dicha empresa con un subcontratista. Por lo que de dicho artículo podemos desprender los siguientes puntos:

I. La obligación de estar inscrito para poder fungir como contratista. Esto coincide con el Proyecto cuando a la empresa usuaria o principal se le establece la obligación de poder constatar que la empresa tercerizante esté debidamente inscrita para poder contratarla. 
2. La responsabilidad solidaria en caso que la persona natural o jurídica no esté inscrita como empleador y cumplir con las obligaciones sociales.

3. En caso que una persona natural como un caso aislado contrate a una empresa para que le repare o construya su casa, no se debe considerar como empleador.

Para el INSS, este tipo de trabajo tercerizado lo que conlleva es que los trabajadores asuman el riesgo total, porque sus derechos laborales se vulneran al no tener precisado quién realmente es su empleador, no se pagan sus obligaciones sociales, y en caso de realizarlo solo lo pagan por un tiempo determinado en el caso de las obras por un periodo corto de tiempo. Asimismo, buscan capacitar a los mismos trabajadores para que puedan exigir las normas laborales y de higiene y seguridad, puedan estar informados quién realmente es el empleador y quién realmente es el dueño de la obra.

Esta institución otorga un período de gracia a todas las empresas de dos años desde que se constituyen para que puedan organizarse, contratar y empezar trabajos, con el fin de promover la libre empresa; asimismo para ella la empresa usuaria o principal la consideran como el empleador; por lo que pueden realizar fiscalizaciones directas a los lugares de trabajo, es decir donde se está construyendo una obra, afianzados en el Art. 122 de la Ley 974 (1982).

El principal objetivo de fiscalizar las empresas y realizar visitas periódicas al lugar de la construcción, es determinar que todos los trabajadores están inscritos al régimen de seguridad social en base al Art. I, inc. b) del Reglamento de la Ley 975 (1982); realizan capacitaciones a los mismos trabajadores para que puedan ellos mismos hacer valer sus derechos y se cumplan con los deberes de higiene y seguridad en el lugar de trabajo.

\subsection{El rol del Instituto de la Vivienda Rural y Urbana}

De acuerdo a su Ley Orgánica, el INVUR es el órgano rector de la vivienda y su fin es facilitar, 428, Art. 3). Asimismo, es el enlace del cumplimiento de las normas de protección del consumidor de los bienes que ofrece una empresa usuaria o principal en el sector de los edificios habitacionales. $Y$ considera a la empresa usuaria o principal como un Agente Productor de Vivienda, definiéndolo como una "persona natural o jurídica que tiene como finalidad la producción de viviendas" (Acuerdo 00I-2014, Art. 2, inc. a).

Este acuerdo que la define como Agente Productor de Vivienda le otorga ciertos derechos, que en el ámbito que nos concierne, es decir de la construcción, le da la libertad de "negociar y acordar libremente las condiciones contractuales para la construcción, comercialización y venta de viviendas o para la ejecución de las obras con carácter habitacional, siempre que las mismas no contravengan lo dispuesto en la presente normativa" (Acuerdo 00l-20l4, Art. 6, inc. 2). Es decir, como empresa que pueda ofrecer viviendas el INVUR le da libertad de poder fungir como una empresa usuaria o principal donde pueda realizar contratos de construcción con otras empresas que trabajen como tercerizantes. 
En cuanto a los contratos de construcción el INVUR podrá revisar los formatos de los contratos de construcción y venta de vivienda o de ejecución de obras que utilizan los agentes productores de viviendas en las relaciones con sus clientes, y aprobarlos; con el fin de determinar si se están cumpliendo con los derechos del cliente como consumidor, sobre todo en materia de las garantías sobre sistemas de construcción.

\section{Conclusiones}

Del estudio realizado a través de las diferentes normas legales actuales de Nicaragua en el tema de la responsabilidad de las empresas en los contratos tercerizados, principalmente en materia de construcción, podemos concluir:

1. Si bien es cierto que la globalización abre nuevas formas de contratación, no podemos generalizar y dar por un hecho que dichas formas sólo buscan precarizar el trabajo y evitar el incumplimiento de las obligaciones laborales por parte de los empleadores; ya que como hemos visto en la práctica dicha globalización ha abierto nuevos mercados y oportunidades a las empresas para poder competir en el mercado comercial y laboral, específicamente en el ámbito que refiere el presente estudio, la construcción.

2. No existe dentro de la legislación comercial ni laboral en Nicaragua la regulación de la figura de la tercerización ni de su implementación, lo que conlleva a que no exista claridad entre las instituciones públicas y privadas acerca de las diferencias y alcances de la tercerización, subcontratación e intermediación, no obstante que las dos últimas figuras están reguladas en el Derecho Laboral Sustantivo y de Seguridad Social.

3. El Proyecto de Ley General de la Tercerización, Subcontratación e Intermediación del Empleo no ha sido estudiado ni abordado desde su presentación, existiendo dentro de su cuerpo normativo confusiones conceptuales entre las figuras que aborda, perjudicando el cumplimiento de los derechos laborales principalmente al momento de establecer claramente quién es el empleador directo en la relación triangular surgida a raíz de los contratos de mano de obra de construcción.

4. Es necesario la aprobación de la Ley General de la Tercerización, Subcontratación e Intermediación del Empleo, donde se establezcan los requisitos para operar como empresa tercerizante a la luz del cumplimiento de los derechos laborales de la mano de obra, principalmente en el sector construcción.

5. El CT (1996) establece la responsabilidad solidaria de las empresas relacionadas respecto a la figura de la subcontratación, sin embargo el Código Procesal del Trabajo y de la Seguridad Social de Nicaragua (20I2) establece un presupuesto procesal previo y es que trabajador pueden demandar subsidiariamente a la empresa principal y será el Juez quien determinará en la sentencia definitiva la responsabilidad solidaria.

6. En la práctica existe sigilo dentro del gremio desarrollador y constructor en cuanto a la publicación de los contratos de mano de obra para los proyectos habitacionales y comerciales, ya que todavía existe recelo en la forma que le exigirán las instituciones el cumplimiento de las obligaciones de índole laboral y de seguridad con los trabajadores 
que las constructoras contratan; esto como respuesta de la confusión que existe entre las figuras de tercerización, subcontratación e intermediación.

\section{Recomendaciones}

En base al estudio realizado y a las conclusiones redactadas, se hace importante destacar algunas recomendaciones para la mejor regulación de la figura de la tercerización en nuestra legislación, y sobre todo en el ámbito de construcción:

I. Aprobar una Ley General de Tercerización, donde se normalice únicamente esta figura, tomando en cuenta que la subcontratación e intermediación se encuentra regulada en nuestra legislación laboral; tomando como línea de referencias la Ley No. 29245: Ley que regula los servicios de tercerización (2008) de Perú siendo esta la más completa entre las legislaciones comparadas y que aborda la figura desde su propio ámbito de aplicación.

2. Regular la tercerización en concordancia con las diferentes instituciones activas en materia de derechos y obligaciones laborales y sociales dejando, claramente, definido que la tercerización opera cuando la empresa principal cede a un tercero parte de las actividades propias del giro del negocio, con el fin de evitar confusión con las figuras de la subcontratación, intermediación o un contrato de servicios.

3. Establecer en la Ley General de Tercerización las obligaciones y derechos de las empresas usuarias o principal y tercerizante, unificando las establecidas en el CT (1996) y la Ley General de Higiene y Seguridad del Trabajo (2007) así como los demás cuerpos normativos que trata de regular bajo la óptica de la subcontratación. Así como los requisitos generales y específicos de las empresas tercerizantes al momento de inscribirse como tal.

4. Definir la creación del área dentro del MITRAB que vele por el cumplimiento de los requisitos generales y las obligaciones de índole laboral y seguridad social con sus trabajadores de las empresas que realicen actividades de tercerización.

5. Establecer dentro de la ley el procedimiento y plazos perentorios para el pago de la fianza presentada ante una Institución Financiera de Nicaragua y bajo la vigilancia del MITRAB en caso de incumplimiento de las obligaciones laborales.

6. Definir como causal de terminación del contrato entre la empresa usuaria o principal y tercerizante el incumplimiento de las obligaciones de índole laboral y de seguridad social.

7. A nivel de las relaciones triangulares, establecer la obligación de las empresas tercerizantes de presentar mensualmente copia de los diferentes documentos que relacionan el cumplimiento de las prestaciones laborales, sociales y de seguridad e higiene.

8. Que las empresas principales o usuarias incluyan en los contratos de tercerización una garantía de cumplimiento, para asegurar el pago de las obligaciones de índole laboral por parte de la empresa tercerizante, la cual tenga una vigencia hasta tres meses después de finalizada la obra. 


\section{Lista de referencias}

Asamblea Nacional. Iniciativa de Ley. (2009). Ley General de Regulación y Ordenamiento de la Tercerización, Subcontratación e Intermediación del Empleo. Nicaragua.

Asamblea Nacional. Iniciativa de Ley. (2009). Ley Tutelar de los Derechos Laborales en las formas alternativas de contratación de Trabajo. Nicaragua.

Banco Central de Nicaragua. (2016). Índice Mensual de Actividad Económica Enero 2016. Nicaragua.

Recuperado

de http://www.bcn.gob.ni/publicaciones/periodicidad/mensual/imae/0 I l 6/informe. pdf

Banco Central de Nicaragua. (20I5). Informe de Construcción Privada. III Trimestre 20I5. División Económica. Nicaragua. Recuperado de http://www.bcn.gob.ni/publicaciones/periodicidad/trimestral/construccion/cons truccion_3.pdf

Bolaños, A. (20I2). La aplicación de los contratos de outsorcing. (Tesis inédita de maestría). Universidad Centroamericana, Managua, Nicaragua.

Cámara Nicaragüense de la Construcción. (20l4). Estadísticas Públicas y Privadas. Edificaciones privadas: Área efectivamente construida I. Nicaragua. Recuperado de http://www.construccion.org.ni/wp-content/uploads/2014/05/Area-

Efectivamente-Construida-2014.pdf

Cámara de la Construcción de Nicaragua. (2007). Convenio Colectivo del Sector Construcción. Nicaragua.

Castillo, J. (2010). Análisis jurídico del contrato de outsorcing en Nicaragua. (Tesis inédita de maestría). Universidad Centroamericana, Managua, Nicaragua.

Código Civil de la República de Nicaragua. Publicado en La Gaceta Diario Oficial No. 2148 del 5 de febrero de 1904. Nicaragua.

Decreto No. 974. Ley de Seguridad Social. Publicado en La Gaceta Diario Oficial No. 49 del 01 de marzo de 1982. Nicaragua.

Decreto No. 975. Reglamento General de la Ley de Seguridad Social. Publicado en La Gaceta Diario Oficial No. 49 del 01 de marzo de 1982. Nicaragua.

Decreto Supremo No. 006-2008-TR. Reglamento de la Ley No. 29245 y del Decreto Legislativo No. 1038. Publicada el 12 de septiembre del 2008. Perú.

Díaz, L., Ureta, L., \& Xalambrí, A. (20I2). La Regulación de las Tercerizaciones en la Empresa y los controles a efectuar. Cátedra de Relaciones Laborales, Universidad de la República. Uruguay. Recuperado de http://virtual.uca.edu.ni/mod/folder/view.php?id=251993

García M., K. (20I5). Dilución de la responsabilidad de las empresas urbanizadoras dentro del sistema de derecho de consumo y la responsabilidad civil. (Tesis inédita de maestría). Universidad Centroamericana, Managua, Nicaragua.

Gobierno de Chile. (2016). Dirección del Trabajo. Código del Trabajo de Chile. Gobierno de Chile. Edición actualizada al 8 de febrero de 2016. Chile.

Herrera, J. \& Guzmán, J. (20I4). Contratos Civiles y Mercantiles. Nicaragua. $3^{\text {a }}$ Edición. Facultad de Ciencias Jurídicas. Universidad Centroamericana. 
Humeres, H. (s.f.). La Tercerización del Trabajo en Chile. Facultad de Derecho. Universidad de Chile. Recuperado de http://virtual.uca.edu.ni/mod/folder/view.php?id=251993

Instituto de la Vivienda Urbana y Rural. Acuerdo Administrativo No. 00I-20l4. Normativa de Derechos del Consumidor o Usuario en el Sector Vivienda. Publicado en La Gaceta Diario Oficinal No. 57 del 25 de marzo de 2014. Nicaragua.

Instituto de la Vivienda Urbana y Rural. (2015). Observatorio Urbano Habitacional. Nicaragua. Recuperado de http://www.invur.gob.ni/

Instituto de la Vivienda Urbana y Rural. (20I5). Principales Logros 2015 y Desafios 2016. Nicaragua. Recuperado de http://www.invur.gob.ni/

Instituto Nacional de Estadísticas y Censo. (2005). Clasificador Uniforme de las Actividades Económicas de Nicaragua (CUAEN). Nicaragua. Recuperado de http://www.inide.gob.ni/censos2005/cuaen/cuaen.pdf

Ley No. 185. Código del Trabajo. Publicada en La Gaceta Diario Oficial No. 205 del 30 de octubre de 1996. Nicaragua.

Ley No. 428. Ley Orgánica del Instituto de la Vivienda Urbana y Rural (INVUR). Publicada en La Gaceta Diario Oficial No. 109 del 12 de junio del 2002. Nicaragua.

Ley No. 618. Ley General de Higiene y Seguridad del Trabajo. Publicada en La Gaceta Diario Oficial No. 133 del 13 de Julio del 2007. Nicaragua.

Ley No. 664. Ley General de Inspección del Trabajo. Publicada en La Gaceta Diario Oficial No. 180 del 19 de septiembre del 2008. Nicaragua.

Ley 677. Ley especial para el fomento de la construcción de vivienda y de acceso a la vivienda de interés social. Publicada en La Gaceta Diario Oficial No. 80 y 81 de los días 04 y 05 de mayo del 2009. Nicaragua.

Ley No. 815. Código Procesal del Trabajo y de la Seguridad Social de Nicaragua. Publicada en La Gaceta Diario Oficial No. 229 del 29 de noviembre del 2012. Nicaragua.

Ley No. 842. Ley de Protección de los Derechos de las Personas Consumidoras y Usuarias. Publicada en La Gaceta Diario Oficial No. 129 del II de julio del 2013. Nicaragua.

Ley No. 18.099. Derechos de los trabajadores. Aprobada el 24 de enero del 2007. Uruguay.

Ley No. 18.25I. Responsabilidad laboral en los procesos de descentralización empresarial. Publicada el 17 de enero del 2008. Uruguay.

Ley No. 29245. Ley que regula los servicios de tercerización. Publicada el 26 de junio del 2008. Perú.

Malespín, F. Septiembre, 20I0. La globalización y el Derecho Laboral. Presentada en la VII Jornada Universitaria. Universidad Centroamericana.

Murcia, D. \& Rovira, X. (1992). La responsabilidad civil en el ámbito de la construcción. Colombia. Pontificia Universidad Javeriana. Facultad de Ciencias Jurídicas y Socioeconómicas.

Organización Internacional del Trabajo. (s.f.). Convenio relativo a la igualdad de remuneración entre la mano de obras masculina y la mano de obra femenina por un 
trabajo de igual valor. Entrada en vigor el 23 de mayo de 1953. Ginebra. Recuperado de

http://www.ilo.org/dyn/normlex/es/f?p=NORMLEXPUB:12100:0::NO::P I 2100 _ LO CODE:CIOO

Organización Internacional del Trabajo. (2009). Descentralización, tercerización, subcontratación. Uruguay: Autor. 